\title{
A retrospective study of 225 cases on cysts and tumors of oral cavity in a dental hospital
}

\author{
Hanumakonda Soundarya ${ }^{1 *}$, Marri Swetha ${ }^{2}$, Malella Bhashitha ${ }^{3}$, Gurram Koutilya Reddy ${ }^{4}$, Harsha Mudigonda ${ }^{5}$ \\ ${ }^{1-5}$ Intern, Dept. of Oral Medicine and Radiology, Malla Reddy Institute of Dental Sciences, Telangana, India \\ *Corresponding Author: Hanumakonda Soundarya \\ Email: soundarya6666@gmail.com
}

\begin{abstract}
Introduction: Aim of the retrospective study is to determine the type and frequency of the cysts and tumors in the oral cavity and to assess their sex, age and site distribution.

Materials and Methods: Study was conducted based on clinical data collected year wise during 2015 to 2018 of all the patients with cysts and tumors under the categories of age, sex and site distribution.

Results: study group consists of total 225 patients, out of which $76(33.77 \%)$ were females and rest $149(66.22 \%)$ were males. The most common cyst is the radicular cyst which shows high frequency among the male patients, most common site of distribution is maxilla and commonly seen during second decade of life. Among the tumors ameloblastoma shows female predilection and occurs most commonly during fourth decade of life.

Conclusion: We observed marked geographical variation in the incidences of various cysts and tumors. According to this study, cyst occurs more frequently than tumors in the oral cavity and the most common cyst is radicular cyst whereas among the tumor, ameloblastoma occupies the first position in frequency.
\end{abstract}

Keywords: Cysts, Tumors, Oral cavity, Frequency distribution, Odontogenic, Pseudo-cyst.

\section{Introduction}

A cyst is an epithelial lined cavity filled with fluid or a soft material and usually grows from the internal pressure generated by the fluid being drawn into the cavity from osmosis. ${ }^{1}$ Cysts of the oral cavity that are lined by epithelium are known as true cysts, whereas which are not lined by epithelium are generally referred to as pseudocysts.

A tumor is defined as an abnormal benign or malignant new growth of tissue that possesses no physiological function and arises from uncontrolled usually rapid cellular proliferation. Odontogenic tumors constitute a heterogeneous group of lesions with histopathological characteristics and diverse clinical manifestations derived from tooth forming apparatus, either are epithelial or ectomesenchymal or both. ${ }^{2}$

Oral cavity, just like any other organ of the body is targeted by a wide variety of cysts and tumors that may vary in etiology, site, and distribution as well as in clinical and histological manifestation. These require careful evaluation so as to arrive at the correct diagnosis and treatment plan accordingly. The aim of this study was to determine the frequency of cysts and tumors diagnosed at Malla Reddy institute of dental sciences in Telangana and compare our findings with other studies reported in other parts of the world.

\section{Materials and Methods}

Retrospective study was conducted based on year-wise data collected from the hospital records of all the patients who has sustained cysts and tumors during 2015 to 2018, under the categories of age, sex and site with its frequency, which were documented in the department of oral medicine and radiology at Malla Reddy institute of dental sciences in Telangana. World Health Organization (WHO) criteria was adopted for the classification of cysts and tumors. And also pseudocyst mucocele is also included.

\section{Results}

The study group consists of total 225 patients which were categorized underage, sex, and site of which 76(33.77\%) patients were females and 149(66.22\%) patients were males. Gender distribution of cysts and tumors in the oral cavity are shown in Table 1. Based on the distribution cyst are most commonly seen in males (67.24\%) than females (32.75). A Radicular cyst which was more common among all the cyst in the study shows more prevalence for males i.e. 70 patients $(76.92 \%)$ than females i.e. 21 patients $(23.07 \%)$ and the Dentigerous cyst $(64.51 \%)$, residual cyst $(100 \%)$ and lateral periodontal cyst $(66.66 \%)$ shows more prevalence in males than females whereas nasolabial cyst $(100 \%)$ and the mucocele $(51.21 \%)$ which is the pseudocyst shows female predilection.

Among the Odontogenic tumor, ameloblastoma was found to be more common in females $(64.70 \%)$ than males $(35.29 \%)$, whereas squamous cell carcinoma (73.33) and KOT $(62.5 \%)$ found to be more common in males than females and among the non-odontogenic tumor-like hemangioma and fibro-osseous lesions, hemangioma shows more prevalence towards females $(66.6 \%)$ and fibro-osseous lesions are more common in males $(62.5 \%)$ among the patients which were recorded from the hospital.

Site distribution of the cysts of the oral cavity is shown in Table 2. Radicular cyst was found to show a greater predilection towards maxilla $(61.53 \%)$ than mandible $(38.46 \%)$. Dentigerous cyst is found to be more common in the mandible $(61.29 \%)$ than maxilla $(38.70 \%)$ whereas the rest, residual cyst, nasolabial cyst, and lateral periodontal cyst show more of occurrence in maxilla rather than mandible. 
Table 1: Gender distribution of cysts and tumors of oral cavity

\begin{tabular}{|l|c|c|c|c|}
\hline Type of lesion & Males & Females & Total no. of patients & Standard deviation \\
\hline CYSTS: & & & & \\
\hline Dentigerous cyst & $20(64.51 \%)$ & $11(35.48 \%)$ & $31(100 \%)$ & 6.36 \\
\hline Radicular cyst & $70(76.92 \%)$ & $21(23.07 \%)$ & $91(100 \%)$ & 34.64 \\
\hline Residual cyst & $3(100 \%)$ & 0 & $3(100 \%)$ & 2.12 \\
\hline Nasopalatine cyst & 0 & 0 & 0 & 0 \\
\hline Nasolabial cyst & 0 & $2(100 \%)$ & $2(100 \%)$ & 1.41 \\
\hline Lateral periodontal cyst & $4(66.66 \%)$ & $2(33.33 \%)$ & $6(100 \%)$ & 1.41 \\
\hline Pseudo- cyst(mucocele) & $20(48.78 \%)$ & $21(51.21 \%)$ & $41(100 \%)$ & 0.70 \\
\hline TUMORS: & & & & 3.53 \\
\hline Ameloblastoma & $6(35.29 \%)$ & $11(64.70 \%)$ & $17(100 \%)$ & 0 \\
\hline CEOT & 0 & 0 & 0 & 0 \\
\hline Pleomorphic adenoma & $2(50 \%)$ & $2(50 \%)$ & $4(100 \%)$ & 0 \\
\hline Squamous cell carcinoma & $11(73.33 \%)$ & $4(26.66 \%)$ & $15(100 \%)$ & 0 \\
\hline Adenoid cystic carcinoma & 0 & 0 & 0 & 0 \\
\hline Muco epidermoid carcinoma & 0 & 0 & 0 & 1.41 \\
\hline KCOT & $5(62.5 \%)$ & $3(37.5 \%)$ & $8(100 \%)$ & \\
\hline Tumor Like:- & \multicolumn{2}{|c|}{} & $3(100 \%)$ & 0.70 \\
\hline Hemangioma & $1(33.33 \%)$ & $2(66.66 \%)$ & $8(100 \%)$ & 1.41 \\
\hline Fibro-osseous lesion & $5(62.5 \%)$ & $3(37.5 \%)$ & & \\
\hline
\end{tabular}

Table 3 shows the age distribution of cysts and tumors of the oral cavity. Dentigerous cyst $(45.16 \%)$, radicular cyst $(46.15 \%)$ and residual cyst $(66.66 \%)$ are seen more commonly between the age groups of 21-30 years of age whereas lateral periodontal cyst is also more commonly seen in the age group between 31-40 years of age (66.66\%) and nasolabial cyst is mostly seen during fifth decade of life. Among the tumors, ameloblastoma is more commonly seen in the age group between $31-40$ years $(58.82 \%)$. Squamous cell carcinoma is mostly seen in the age group of 51-60 years $(60 \%)$ and Keratocystic odontogenic tumor most commonly occurs between age group of 21-30 years $(62.5 \%)$ and both hemangioma (66.66\%) and fibro-osseous lesion $(50 \%)$ which is non-odontogenic tumor-like lesions are commonly seen in between age group of 31-40 years.

\section{Discussion}

This paper targets the updating of frequency, demographical characters of cysts and tumors of the oral cavity in our teaching hospital at Hyderabad, during a span of 4 years (2015-2018). With regard to a comparison of the results of this retrospective study with those published by other authors reveals several similarities and differences.

According to the gender comparison where the radicular cyst is most common cyst among all the cyst of oral cavity shows more prevalence towards male patients $(76.92 \%)$, this finding differs from the studies reported by luivillasis Sarmiento et al., ${ }^{3}$ GO Bassey et al., ${ }^{4}$ and however shows similarities with the studies of Prashanth Ramachandra et al., ${ }^{5}$ Monika Aroquiadasse et al., ${ }^{6}$ Niranjan $\mathrm{KC}$ et al. ${ }^{2}$ and Soudabeh Sargolzaei et al. ${ }^{7}$ Dentigerous cyst $(64.51 \%)$ and lateral periodontal cyst $(66.66 \%)$ were found to occur more commonly in males in this study and show agreement with the studies of Soudabeh Sargolzaei at al. ${ }^{7}$ and differs with the studies of Monika Aroquiadasse et al., ${ }^{6}$

Luivillasis Sarmiento et al. ${ }^{3}$ as they show lateral periodontal cyst has more prevalence in female population

Ameloblastoma which is a true neoplasm of enamel organ type tissue which does not undergo differentiation to the point of enamel formation. It is the most common tumors of oral cavity according to this study shows higher incidence of occurrence in female patients $(64.70 \%)$ which correlates with the studies of Monika Aroquiadasse et al., ${ }^{6}$ Niranjan KC et al. ${ }^{2}$ and differ from the studies of Manisha $\mathrm{S}$ Ahire et al., ${ }^{8}$ Ajinkya Varkhede et al., ${ }^{9}$ GO Bassey et al. ${ }^{4}$ where they show male predilection more. Squamous cell carcinoma occurs more commonly in males $(73.33 \%)$ as similar to the studies of Paolo G Arduino et al. ${ }^{10}$ Monika Aroquiadasse et al. ${ }^{6}$

Dentigerous cyst which is known as Odontogenic cyst that is commonly associated with impacted tooth is most commonly occurs during the third decade of life $(45.16 \%)$ these findings differ from the studies of Monika Aroquiadasse et al. ${ }^{6}$ where it is more common in the second decade and also differ from Hyun-Kyung lee et al. ${ }^{1}$ and GO Bassey et al. ${ }^{4}$ studies and correlates with Prashanth Ramachandra et al. ${ }^{5}$ study. Radicular cyst shows the highest frequency during 21-30 years of age and the findings are similar to the findings of Monika Aroquiadasse et al. ${ }^{6}$ study. Among the tumors, ameloblastoma shows high occurrence during 31-40 years of age (58.82\%) which correlates with the studies of Monika Aroquiadasse et al. ${ }^{6}$ and Ajinkya Varkhede et al. ${ }^{9}$

According to the site distribution of cysts of the oral cavity, Dentigerous cyst most commonly located in the mandibular region showing frequency of $61.29 \%$ which shows similar findings with the studies of Prashanth 
Ramachandra et al., ${ }^{5}$ Hyun-Kyung lee et al. ${ }^{1}$ and Luivillasis

Sarmiento et al. ${ }^{3}$

Table 2: Site distribution of cysts of oral cavity

\begin{tabular}{|l|c|c|c|c|}
\hline Type of lesion & Maxilla & Mandible & Total no. & Standard deviation \\
\hline Dentigerous cyst & $12(38.70 \%)$ & $19(61.29 \%)$ & $31(100 \%)$ & 4.94 \\
\hline Radicular cyst & $56(61.53 \%)$ & $35(38.46 \%)$ & $91(100 \%)$ & 14.84 \\
\hline Residual cyst & $3(100 \%)$ & 0 & $3(100 \%)$ & 2.12 \\
\hline Nasolabial cyst & $2(100 \%)$ & 0 & $2(100 \%)$ & 1.41 \\
\hline Lateral periodontal cyst & $4(66.66 \%)$ & $2(33.33 \%)$ & $6(100 \%)$ & 1.41 \\
\hline
\end{tabular}

Table 3: Age distribution of cysts and tumors of oral cavity

\begin{tabular}{|l|c|c|c|c|c|c|c|c|c|}
\hline Type of lesion & $\mathbf{1 0 - 2 0}$ years & $\mathbf{2 1 - 3 0}$ Years & $\mathbf{3 1 - 4 0}$ Years & $\mathbf{4 1 - 5 0}$ Years & $\mathbf{5 1 - 6 0}$ Years & $\begin{array}{c}\mathbf{6 1 - 7 0} \\
\text { Years }\end{array}$ & $\begin{array}{c}\text { Above 70 } \\
\text { Years }\end{array}$ & $\begin{array}{c}\text { Total no. } \\
\begin{array}{l}\text { Standard } \\
\text { deviation }\end{array}\end{array}$ \\
\hline $\begin{array}{l}\text { Cysts:- } \\
\text { Dentigerous } \\
\text { cyst }\end{array}$ & $11(35.48 \%)$ & $14(45.16 \%)$ & $4(12.90 \%)$ & 0 & $2(6.45 \%)$ & 0 & 0 & $31(100 \%)$ & 5.76 \\
\hline Radicular cyst & $11(12.08 \%)$ & $42(46.15 \%)$ & $21(23.07 \%)$ & $4(4.39 \%)$ & $6(6.59 \%)$ & $4(4.39 \%)$ & $3(3.29 \%)$ & $91(100 \%)$ & 14.25 \\
\hline Residual cyst & 0 & $2(66.66 \%)$ & 0 & 0 & $1(33.33 \%)$ & 0 & 0 & $3(100 \%)$ & 0.78 \\
\hline Nasolabial cyst & 0 & 0 & 0 & $2(100 \%)$ & 0 & 0 & 0 & $2(100 \%)$ & 0.75 \\
\hline $\begin{array}{l}\text { Lateral } \\
\text { periodontal cyst }\end{array}$ & 0 & $2(33.33 \%)$ & $4(66.66 \%)$ & 0 & 0 & 0 & 0 & $6(100 \%)$ & 1.57 \\
\hline Tumors: & & & & & & & & & \\
\hline Ameloblastoma & 0 & $3(17.64 \%)$ & $10(58.82 \%)$ & $4(23.52 \%)$ & 0 & 0 & 0 & $17(100 \%)$ & 3.73 \\
\hline $\begin{array}{l}\text { Pleomorphic } \\
\text { adenoma }\end{array}$ & 0 & 0 & 0 & $2(50 \%)$ & $2(50 \%)$ & 0 & 0 & $4(100 \%)$ & 0.97 \\
\hline SCC & 0 & 0 & 0 & $6(40 \%)$ & $9(60 \%)$ & 0 & 0 & $15(100 \%)$ & 3.76 \\
\hline KCOT & 0 & $5(62.5 \%)$ & $2(25 \%)$ & $1(12.5 \%)$ & 0 & 0 & 0 & $8(100 \%)$ & 1.86 \\
\hline tumor like:- & & & & & & & & \\
\hline Hemangioma & 0 & $1(33.33 \%)$ & $2(66.66 \%)$ & 0 & 0 & 0 & 0 & $3(100 \%)$ & 0.78 \\
\hline $\begin{array}{l}\text { Fibro- osseous } \\
\text { lesions }\end{array}$ & 0 & $3(37.5 \%)$ & $4(50 \%)$ & $1(12.5 \%)$ & 0 & 0 & 0 & $8(100 \%)$ & 1.67 \\
\hline
\end{tabular}

Radicular cyst $(61.53 \%)$ and lateral periodontal cyst $(66.66 \%)$ more frequently occur in maxillary region which shows similar findings with Monika Aroquiadasse et al, ${ }^{6}$ Hyun-Kyung lee et al., ${ }^{1}$ Prashanth Ramachandra et al. ${ }^{5}$ and Luivillasis Sarmiento et $\mathrm{al}^{3}{ }^{3}$ studies. Residual and nasaolabial cyst are also more common in maxillary region according to this study.

\section{Conclusion}

We observed marked geographical variation in the incidences of various cysts and tumors. According to this study, cyst occurs more frequently than tumors in the oral cavity and the most common cyst is radicular cyst whereas most common tumor is ameloblastoma. Since most of the data on the frequency of cysts and tumors are derived from hospital-based institution which may show some biases while collecting information from the patients or from the old records of the hospital.

\section{Conflict of Interest: None.}

\section{References}

1. Lee, Hyun-Kyung, Kyung-Sun Ryu, Moo-Gun Kim, KwangWon Park, Ryun-Ga Kim, Sang-Hwa Roh, Tae-Young Jung, and Sang-Jun Park. Retrospective Study of Cysts in the Oral and Maxillofacial Regions: Statistical and Clinical Analysis. $J$ Korean Assoc Maxillofac Plast Reconstr Surg 2014;36(1):1-6.
2. K C, Niranjan, Shaikh, Zulfin. Clinicopathological correlation of odontogenic cysts and tumours in a South Indian population over a 20-year period. Int J Dent Res 2014;2(2):32-6.

3. Villasis-Sarmiento L, Portilla-Robertson J, Melendez-Ocampo A, Gai- tan-Cepeda LA, Leyva-Huerta ER. Prevalence and distribution of odontogenic cysts in a Mexican sample. A 753 cases study. J Clin Exp Dent 2017;9(4):531-8.

4. Bassey GO, Osunde OD, Anyanechi CE. Maxillofacial tumors and tumor-like lesions in a Nigerian teaching hospital: an eleven year retrospective analysis. Afr Health Sci 2014;14(1):56-63.

5. Ramachandra P, Maligi P, Raghuveer H P. A cumulative analysis of odontogenic cysts from major dental institutions of Bangalore city: A study of 252 cases. J Oral Maxillofac Pathol 2011;15(1):1-5.

6. Aroquiadasse M, Daniel MJ, Srinivasan SV, Jimsha VK, Modha J, Pancharethinam D. A retrospective study of cysts and tumors of the oral cavity. J Indian Acad Oral Med Radiol 2017;29(1):2-6.

7. Sargolzaei S, Hassanzadeh M, Eshghyar N, Taghavi N, Akbarzadeh A. Odontogenic Cysts: A 10-Year Retrospective Study in an Iranian Population. J Dent Sch 2016;34(3):147-56.

8. Ahire MS, Tupkari JV, Chettiankandy TJ, Thakur A, Agrawal RR. Odontogenic tumors: A 35-year retrospective study of 250 cases in an Indian (Maharashtra) teaching institute. Indian $J$ Cancer 2018;55(3):265-72.

9. Varkhede A, Tupkari JV, Sardar M. Odontogenic tumors: A study of 120 cases in an Indian teaching hospital. Med Oral Patol Oral Cir Bucal 2011;16(7):895-9. 
10. Arduino, Paolo G; Carrozzo, Marco; Chiecchio, Andrea; Broccoletti, Roberto; Tirone, Federico; Borra, Eleonora; Bertolusso, Giorgio; Gandolfo, Sergio. Clinical and Histopathologic Independent Prognostic Factors in Oral Squamous Cell Carcinoma: A Retrospective Study of 334 Cases. J Oral Maxillofac Surg 2009;66(8):1570-9.

11. Williams AO, Browne RM, Akinosi JO. Fibro-osseous lesions of the jaw in Nigeria. J Natl Med Assoc 1974;66(3):185-91.

12. de Medeiros WK, da Silva LP, Santos PP, Pinto LP, de Souza LB. Clinicopathological analysis of odontogenic tumors over 22 years period: Experience of a single center in northeastern Brazil. Med Oral Patol Oral Cir Bucal 2018;23(6):664-71.

13. Deepthi P V, Beena V T, Padmakumar S K, Rajeev R, Sivakumar R. A study of 1177 odontogenic lesions in a South Kerala population. J Oral Maxillofac Pathol 2016;20:202-7.

14. Bhagwat A, Barpande S R, Bhavthankar J D, Mandale M S, Humbe J, Singh P. Odontogenic tumors: Review of 127 cases in Marathwada region of Maharashtra. J Oral Maxillofac Pathol 2017;21:457-8.

15. Lima-Verde-Osterne R, Turatti E, Cordeiro-Teixeira R, Barroso-Cavalcante $\mathrm{R}$. The relative frequency of odontogenic tumors: A study of 376 cases in a Brazilian population. Med Oral Patol Oral Cir Bucal 2017;22(2):e193-e200.

16. da Silva LP, Serpa MS, Tenório JR, do Nascimento GJ, de Souza-Andrade ES, Veras-Sobral AP. Retrospective study of 289 odontogenic tumors in a Brazilian population. Med Oral Patol Oral Cir Bucal 2016;21(3):e271-e5.

17. Sekerci AE, Nazlim S, Etoz M, Deniz K, Yasa Y. Odontogenic tumors: a collaborative study of 218 cases diagnosed over 12 years and comprehensive review of the literature. Med Oral Patol Oral Cir Bucal 2014;20(1):e34-e44.

How to cite this article: Soundarya $\mathrm{H}$, Swetha, M Bhashitha M, Reddy GK, Mudigonda H. A retrospective study of 225 cases on cystsand tumors of oral cavity in a dental hospital. J Oral Med, Oral Surg, Oral Pathol, Oral Radiol 2019;5(2):33-6. 